\title{
Perceptions of pregnant teenagers with regard to the antenatal care clinic environment
}

\author{
Authors: \\ Sindiwe James ${ }^{1}$ \\ Nadine Rall ${ }^{1}$ \\ Juanita Strümpher ${ }^{1}$ \\ Affiliations: \\ ${ }^{1}$ Department of Nursing \\ Science, Nelson Mandela \\ Metropolitan University, \\ South Africa \\ Correspondence to: \\ Sindiwe James \\ Email: \\ sindiwe.james@nmmu.ac.za \\ Postal address: \\ 2nd Floor, R Block, North \\ Campus, Summerstrand, \\ Nelson Mandela Bay 6031 \\ South Africa \\ Dates: \\ Received: 15 Aug. 2011 \\ Accepted: 07 Aug. 2012 \\ Published: 12 Oct. 2012 \\ How to cite this article: \\ James, S., Rall, N. \& \\ Strümpher, J., 2012, \\ 'Perceptions of pregnant \\ teenagers with regard to \\ the antenatal care clinic \\ environment', Curationis \\ 35(1), Art. \#43, 8 pages. \\ http://dx.doi.org/10.4102/ \\ curationis.v35i1.43
}

(C) 2012. The Authors.

Licensee: AOSIS

OpenJournals. This work

is licensed under the

Creative Commons

Attribution License.
Pregnancy in teenagers seems to be a challenge that might contribute to a struggle to fulfil the objectives of the Millennium Development Goals directly related to women's reproductive health and neonatal care. The challenge becomes worse as midwives and nurses find it difficult to fully supervise all these pregnancies, because teenagers stay away or default from clinic attendance. The purpose of the study was to explore and describe the perceptions of pregnant teenagers of the antenatal care (ANC) clinic environment and to recommend guidelines to midwifery operational managers for strategies to create teenager-friendly ANC clinic environments. The study applied a qualitative research design with explorative, descriptive and contextual research approaches. The ethical principles that guided this study were respect for the person, beneficence and justice. Semi-structured interviews utilising a predetermined interview schedule with a central open-ended question to address the study objectives were used. Data were collected from pregnant teenagers attending ANC clinics in Nelson Mandela Metropolitan Municipality. Participants were unanimous in that they perceived the clinic environment as causing discomfort to them. Different reasons attributed to this experience were related to their young age. The age difference between themselves and other women attending the clinic made participants perceive themselves as inferior and as being treated as such at the clinic. They found this embarrassing and recommended having their own waiting area and additional midwives at the clinic so that they would not be subjected to humiliating scrutiny and disapproval from older pregnant women. Pregnant teenagers' recall of their experiences of the ANC clinic environment suggests that they perceive themselves as not being adequately cared for, as judged, and as forced to be in an environment that is insensitive to their needs. As a result some of their peers stayed away from the clinic and at times they contemplated the same action. A well-managed ANC clinic environment which has midwives who are empowered with the necessary skills in terms of dealing with the needs of youth has been requested by the pregnant teenagers.

\section{Introduction}

\section{Background}

Teenage pregnancy holds many concerns for the pregnant teenager, her unborn foetus, her immediate family and society the world over. Concerns emanate mainly from the fact that, should complications occur during the pregnancy or labour and delivery, two lives are at risk. Globally midwives take their professional responsibility seriously and are encouraging women, especially teenagers, to attend antenatal care (ANC) clinics as soon as they become aware of being pregnant, and to continue doing so until labour commences. At times it becomes a challenge to the midwives to fulfil this goal.

It is general knowledge that globally teenage pregnancy has always been a challenge and that this challenge is still increasing; where a decrease is noted it is at a disturbingly slow rate (Saadhna et al. 2009:22). It is amongst the African countries that this phenomenon and its challenges is mostly apparent (Irinoye et al. 2004:27; Kazembe 2009:69; Omoni 2009:25).

South Africans are currently faced with the challenge of increasing numbers of teenagers getting pregnant, whether at school or not, thus making it difficult to relate effects of schooling to pregnant teenagers and dropping out of school before completing their studies. The increase is informally associated with the Child Support Grant offered by the Government as a social support to the children; the Human Sciences Research Council disputes this, further explaining that teenage pregnancy in South Africa peaked from 1996, two years before the introduction of the grant (Saadhna et al. 2009).

Statistics released by the Human Sciences Research Council (Saadhna et al. 2009:23) on behalf of the National Department of Education show a teenage pregnancy rate of $58 \%$ amongst learners during the period 2004-2008, with the rate of pregnancy amongst those not at school averaging 
35\%. The Eastern Cape Province, which is where the study was conducted, takes the lead with a pregnancy rate of $69 \%$ in a sample of 11852. In the opinion of the authors of this article, such results imply that dropping out of school carries a high risk of teenage pregnancy.

A survey conducted in the Eastern Cape Province by the Department of Education showed the extent of these raised numbers of teenage pregnancies in this province; in the Queenstown district in 2011 there were as many as 246 teenage pregnancies, in Mthatha district 782, Libode district 918, Grahamstown district 90, East London district 308, King William's Town district 442, and Butterworth district 542 (Majangaza \& Skiti 2011:1). According to this report, 8427 teenagers were pregnant in 2010 compared to 8674 in 2009 in the same province. These pregnancies were in teenagers between the ages of 13 and 19 years, from as early as Grade 3 up to high school.

In a study conducted by Harrison (2008) data analysis indicated that teenage pregnancy increased significantly amongst 17-18-year-olds that were not attending school. This increase has also been noted in the Nelson Mandela Metropole. Notably, recently (October 2011) a child was born from a young teenage mother and was admitted for major surgical interventions to correct gross congenital abnormalities. Most of the mothers of premature infants admitted to one of the hospitals in Port Elizabeth were teenagers.

Attendance at ANC clinics becomes increasingly important in pregnant teenagers as there is scientific evidence confirming that they are prone to severe pregnancy and labour-related complications (James, Van Rooyen \& Strümpher 2010:5). ANC aims to provide the expectant mother with overall supervision of maternal health and provision of education relevant to her confinement and which may increase the survival rate of the child (Sellers 2006a:166). With reference to this aim, Littleton and Engebretson (2002:454) maintain that attendance of an ANC clinic plays an important part in enabling the screening of pregnant mothers for health problems and limiting the possibility of complications. As stated by these authors, ANC clinic attendance allows for early identification of problems and best treatment options to be implemented to correct them.

In South Africa one of the ANC educational programmes aimed at improving ANC focuses on providing basic ANC (BANC) (Pattison 2005:9). According to Pattison, BANC aims to ensure that all pregnant mothers attend ANC clinics at least four times during their pregnancy, starting with the first follow-up visit at 20 weeks of gestation (Pattison 2005:9). This programme allows women to be screened in order to make a concrete assessment of whether they are low- or high-risk patients during their pregnancy (Pattison 2005:14). Those who are diagnosed as high-risk or with pregnancy-related complications, and those who may need further care and management, are referred to a tertiary healthcare facility.
Pregnancy-related complications and problems for pregnant teenagers are, for example, anaemia, hypertension and prolonged labour (Fraser \& Cooper 2010:226). According to Cronjé and Grobler (2007:667) complications like pre-term labour, intra-uterine growth restrictions or cephalo-pelvic disproportion are also common in teenage pregnancy. Complications of cephalo-pelvic disproportion may lead to delivery by caesarean section, and this could be fatal if the delivery persists vaginally. It is therefore important that such possible complications be identified and prevented early in the pregnancy of the teenager and the necessary monitoring continued. For that reason, attending ANC clinics is crucial to these teenagers.

To limit maternal and neonatal deaths in South Africa, government has developed and introduced guidelines to be implemented during the care of a maternity patient (Department of Health [DoH] 2006:2), as well as guidelines to manage neonatal emergencies (DoH 2008:4). The National Committee on Confidential Enquiries into Maternal Deaths (NCCEMD) was established by the Minister of Health in 1999 through the National Policy Health Act, No. 116 of 1990, to assist with the objective of developing guidelines to assist with the care of maternity patients (DoH 2006:9). Reports from NCCEMD (DoH 2006:7) revealed poor to non-attendance at ANC clinics by pregnant teenagers, despite free ANC services offered at public institutions. The literature verifies possible reasons that affect attendance at ANC clinics by teenagers (DoH 2006:7; Thompson 2010:368), but there is limited information available as to how pregnant teenagers experience the care at ANC clinics.

At times, encouragement of women to attend ANC clinics is thought not to be successful due to misguided perceptions and attitudes of pregnant women and teenagers. Attitudes range from a feeling of boredom due to lack of enthusiastic facilitation, and feeling that they already know enough about ANC, to a non-conducive clinic environment (Tighe 2010:295). Most importantly, in this study it was identified that lack of knowledge related to ANC clinic attendance was a huge factor, and as a result participants in that study recommended preconception education at school, especially during the secondary school phase (Tighe 2010:298). Some women do not attend or withdraw from the clinic because of 'overenthusiastic' women talking about their own experiences (Tighe 2010:298). Socio-economic factors were also identified as a factor influencing attendance to these health institutions.

\section{Problem statement}

This research study was initiated from the observation made by the researcher (S.J.) that some pregnant teenagers were unbooked or had made only a few visits to the ANC clinic before they were admitted for delivery. Some of these teenagers come as referrals for complications, either in pregnancy or in labour. Teenagers who attended the ANC clinics regularly were more prepared for childbirth than 
those who did not, and if complications were diagnosed and treated early, the outcome of the pregnancy was more likely to be successful for both mother and baby.

The researcher had also observed at some ANC clinics that adult women get preferential attention compared to teenagers, because they have to go back to work or have other commitments to take care of. This happened regardless of the fact that the teenager was booked and had come earlier than the adult women and had to return to school. However, there are clinics that use the 'first come, first served' principle. Health education was provided to all of them at the same time - before or after several women had completed their visit. The researcher observed that by the time the health education was done, most of the teenagers were either not asking questions when the opportunity to do so was provided, or had already left. It was also noted that if health education was given on a one-to-one basis and supported enough, these teenagers usually had a lot to ask. Screening of women in an ANC clinic entails interviews and at times disclosure of personal information, which is often of a sensitive nature, and the staff need time to do this properly.

\section{Research questions}

The research questions that guided the study were as follows:

- What is the perception of teenagers with regard to the ANC clinic environment?

- What improvement can be made to the ANC clinic environment to motivate teenagers to attend the ANC clinic regularly?

\section{Objectives of the study}

The objectives of the study were to:

- explore and describe the perceptions of pregnant teenagers of the ANC clinic environment

- recommend guidelines to midwifery operational managers for strategies to create teenager-friendly ANC clinic environments.

\section{Significance of the study}

A proper understanding of these perceptions through the publication of recommendations from the main study would assist with a strategy to provide a more teenage-friendly ANC clinic environment and enhance motivation to attend. It is hoped that the nurses and/or midwives and teenagers will learn to tolerate each other and meet each other halfway when challenges in this environment occur. International health care communities, which do not necessarily have the same challenges but are also faced with the concern of increased non-clinic attendance by teenagers, might also learn from this article, especially when it comes to dealing with teenage-related health issues.

\section{Research methods and design}

The research methods of the study included: identification of a research setting, data collection methods and data analysis.

\section{Setting}

The study was conducted in the clinics of the Nelson Mandela Metropolitan Municipality.

\section{Design}

The study applied a qualitative research design. To enhance the design the researcher utilised explorative, descriptive and contextual research approaches. Sampling was done anonymously from the ANC clinic attendance registers. These registers did not contain any particulars relating to management of the teenagers, nor any confidential information about them. All names that met the inclusion criteria of the population and who attended the clinic from June 2007 to June 2009 were written down.

After permission for access was granted by relevant authorities, the data collection phase began. Data were collected by means of semi-structured interviews, making observations and writing field notes. The researcher made use of one main question and three sub-questions, which all participants had to respond to. The main question that was asked of each participant was: 'Tell me how it was for you to attend an ANC clinic?', and the predetermined questions were:

- What did you like about the care at your ANC clinic?

- What did you not like about the care at your ANC clinic?

- What kind of ANC would you have liked to have had at the ANC clinic?

\section{Data collection methods}

The data collection method was that of semi-structured interviews over three months. The interviews were conducted in September and October 2009 and completed in March 2010. The clinics that were sampled were those that are attending to low-risk pregnant women, and are in either a 'coloured' or African township. In South Africa pregnancy is common amongst coloured and African teenagers (Kaufman, De Wet \& Stadler 2001:152; Moultrie \& McGrath 2007:21), hence the choice of the two sites for this study. Two clinics from each township were chosen for conducting the study. The clinic had to have a free room that could be used for the interviews, away from the consulting rooms. The interview would take place after the participant had been attended to by the midwife, and this action was agreed upon during the time of fixing the appointment for the interview.

The participants were given a choice as to where the interviews would take place, namely at the clinic or at another venue. All of them chose the clinic as the suitable venue. The participants were asked to describe how they experienced attendance of the ANC clinic. As a predetermined question, they also had to make known to the researcher their preferred form of ANC (Maree 2010:87). The interviews was done by means of semi-structured one-on-one interviews, making observations and writing field notes, which took place in a quiet room away from the rest of the clinic, were captured on audio-tape, and took on average 45 minutes. Twelve 
participants were chosen from a population of pregnant teenagers who were at least 35 weeks pregnant, had attended an ANC clinic at least twice, and who were residents of the Nelson Mandela Metropolitan Municipality. Teenagers who were defaulting from the clinic were initially considered as participants, but it was decided against this with a view to probable challenges related to reasons for withdrawing from the clinic. Challenges thought of were possible miscarriages or premature labour. The researcher aimed at interviewing teenagers of all ages with the necessary permission, but mostly the older teenagers were eager for the interviews. This was a purposive sample (Maree 2010:79).

\section{Data analysis}

Data saturation was the criterion used to discontinue data collection and continue with data analysis (De Vos et al. 2010:294). Interviews were transcribed verbatim and analysed within 12 hours of capturing, according to the method suggested by Creswell (2003:192). The feasibility of the methods of the study were tested using two participants who did not form part of the main study (Gillham 2009:74).

\section{Ethical considerations}

The ethical principles that guided the study were respect for the person, beneficence and justice (Katzenellenbogen, Joubert \& Abool 2002:28). To maintain respect and human dignity, the researcher ensured that the research questions were not more intrusive than they needed to be (Brink, Van Der Walt \& Van Rensburg 2006:33). The participants were informed of their rights of both voluntary participation and termination of that participation at any stage of the research (Botma et al. 2010:277).

For the purpose of the principle of beneficence, the participants were informed that participation had no monetary benefits, but that they would benefit by using the opportunity to make a positive contribution through participation in the study to long-term implications of the care of pregnant teenagers in ANC clinics. The participants were assured that the information gathered from each individual would be kept confidential and that no names would be attached to their responses.

Furthermore, the audio-tapes with interview information were labelled using numbers and dates, and together with transcripts and field notes were kept under lock and key at the researcher's home. Participants were also informed that a copy of the final report of the study would be kept in the library at the Nelson Mandela Metropolitan University, to be viewed by interested parties and published in different midwifery journals. The principle of justice involves including all eligible participants regardless of their language, gender or age, allowing them equal opportunities to participate (Watson et al. 2008:132). For the purpose of this study, set criteria guided the choice of participants and the language to be used.
Permission to conduct the study was granted by the Nelson Mandela Metropolitan University through its Faculty of Health Sciences' Research, Technology and Innovations Committee and the Research Ethics Committee: Human. Furthermore, permission was granted by the Eastern Cape's DoH through its Port Elizabeth regional office. Midwives working at the clinics acted as gate-keepers and assisted with access to the ANC clinic registers. The researcher identified the names and contacted the teenagers telephonically to fix appointments, discuss the merits of the study and ask for permission to participate. The teenagers signed voluntary informed consent forms after the objectives and methods of the study were explained to them but before commencing with the interviews.

\section{Trustworthiness}

To enhance the truth value the researcher made use of Guba's model of trustworthiness (Krefting 1991:215) in the main study. The model includes the aspects of truth value, applicability, consistency and neutrality.

\section{Discussion of results}

Twelve participants were purposively selected using the inclusion criteria. Six participants were Africans and six were coloured teenagers. This selection was purposely made so as to strike a balance between the two cultures where possible. Five participants still attended school, although at the time of the study they had decided to leave school with the intention of going back after delivery of the baby. The other seven participants left school permanently after finding out they were pregnant, and were not sure if they would be going back to school as they needed to first help with care of their babies. Education level at the time of becoming pregnant was for one participant Grade 8, for two Grade 9, for three Grade 10, for three Grade 11 and for another three Grade 12.

Four of the participants had skipped a visit once already; two skipped twice but went back a week thereafter to make up for the lost visit, and were refused access. The rest of the participants were on their third consecutive scheduled visit.

Seven of the participants felt that the ANC clinic environment was making them feel lonely, whilst others felt that the environment caused embarrassment, either because of their young age or because of the organisation of the clinic. A few of the teenagers felt that their negative perceptions of the environment were related to staffing norms. A summary of the findings are provided below (Table 1).

TABLE 1: Perceptions of pregnant teenagers of the antenatal care clinic environment.

\begin{tabular}{ll}
\hline Main theme & Sub-themes \\
\hline $\begin{array}{ll}\text { - Pregnant teenagers felt that the } \\
\text { ante-natal care clinic environment }\end{array}$ & $\begin{array}{l}\text { The pregnant teenagers felt that: } \\
\text { was alienating to them. }\end{array}$ \\
& $\begin{array}{l}\text { - their age difference was a problem } \\
\text { causing them discomfort } \\
\text { - there may have been too few staff } \\
\text { members and too many patients to } \\
\text { take care of. }\end{array}$ \\
\hline
\end{tabular}




\section{Main theme: Pregnant teenagers felt that the ANC clinic environment was alienating to them}

A therapeutic milieu aims to provide patients with a stable environment that assists with facilitation and implementation of individualised treatment plans and providing a structure that entails proper organisation of the service that involves set patient-nursing activities (Stuart \& Laraia 2005:700). The environment should also assist with the validation of each individual patient being recognised by the staff, thus increasing the patient's self-esteem and making them feel better (Stuart \& Laraia 2005:701).

Kotzé (2008:200) refers to a therapeutic milieu as an environment that allows accompaniment and provision of support to those in need of such assistance. This author also emphasises a trusting relationship in order to enhance a therapeutic environment (Kotzé 2008:200). In relation to the importance of a trusting patient-nurse relationship, the positive value of caring is seen as an element of that relationship (Yoder-Wise 2007:439). In this study it seemed as if the clinic environment was not promoting a positive relationship between the participants and the midwives, either because of limited one-on-one contact or because of limited privacy provided.

Relationships in maternity care, as in other types of health care, are at the core of the quality of the care to be provided and that which has been rendered (Hunter et al. 2008:132). According to these authors, a positive relationship facilitates learning in a midwifery setting, which in the context of this study would benefit the participants with the necessary insight into the pregnancy. The participants in this study felt and expressed that the clinic environment was alienating. They did not like to attend the ANC clinics as they perceived them as uncomfortable places that evoked feelings of stress and sadness:

'It makes you lonely and feel lonely. I sit alone there ..., I feel lonely by being there only ... sometimes just wish that I could be at home.' (Participant 4, Grade 9)

The environment was stated as being further negatively influenced by the age difference between women who were attending the ANC clinic, disorganisation of the clinic, which caused discomfort to them, and the concern that there might be too few staff members and too many patients. These mentioned experiences are discussed individually as subthemes to the main theme.

\section{Sub-theme A: The pregnant teenagers felt that the age difference was a problem}

Primary healthcare clinics in the country, and in particular ANC clinics, do not have separate facilities for the assessment of older or younger women. All pregnant women make use of the same facilities and attend the ANC clinic at the same time. According to the clinic staff, the mean age difference between the participants and these older women ranges from five to 11 years.
The participants were very conscious that they were the youngest of the women attending the clinic, and that they were being forced to sit amongst women who were all older than them, making them feel uncomfortable:

'I feel ashamed, because I am just small.' (Participant 5, Grade 8)

'It is not nice, because they are big and you are small.' (Participant 3, Grade 8)

Since teenagers struggle with social pressures and forming their own identities, they explore new ways of expressing themselves (Sellers 2006b:1716). Teenagers are aware of the fact that society frowns on young people participating in unsafe sex, resulting in teenage pregnancies (James et al. 2010:4). For that reason, teenagers may become uncomfortable in the presence of adults, who they think will not understand.

The participants also described how they experienced a feeling of being treated as children, but when they brought their own parents in the midwives gave them better care as they could not easily shout at them in front of their parents. The negative feeling was aggravated by the fact that when care was being rendered, the participants felt that the older women were given preference:

'They want to be first and always helped first and the younger ones has [sic] always to stand aside and we should always be last ... nurses make as if they do not see and call them first in [sic].' (Participant 1, Grade 10)

Individuals may experience loneliness when they feel that their relationships with others are less satisfying than they would like them to be (Taylor, Peplau \& Sears 2003:234). When the participants engaged in conversation with the older women who were attending the clinic, it was not pleasant and at times was embarrassing because of misconceptions related to the pregnancy:

'I came late as I went to school and my teacher gave permission for the time to go to the clinic and I was late, now they say I do not care and that I only want grant now ... it is painful and embarrassing because you just keep quiet because they are older. The nurse also says that but they smile.' (Participant 3, Grade 11)

The participants felt that it would have been less embarrassing for them to attend a special clinic with only pregnant teenagers, or if they were allowed to wait in another area and be separated from the adult women when receiving ANC. One participant actually confessed that at times she would be late for the clinic just to make sure she spent as little time as possible in the presence of the older women. She experienced less anxiety then, which helped her to cope within this stressful environment.

Age difference has been highlighted by several authors as a factor in limited attendance of ANC by young mothers (Thompson 2010:368). This is, according to Thompson (2010:368), because of the perceived disapproval from older women towards the pregnant teenagers, and the fact that at different ages teenagers have different needs which should be viewed independently. Such needs are at times to be successfully met through one-on-one consultation, which in this study seem to be a concern as the participants complained about the organisation of the clinics. 
Sub-theme B: The pregnant teenagers felt that the organisation of the clinic was causing them discomfort

Organisation can be defined as the orderly structure of duties, tasks and responsibilities, and the equal division thereof in a unit ensures that activities occur smoothly within that unit (Muller 2003:138). The benefit of a well-organised unit is that each individual working there will know what is expected from him or her.

The participants expressed concern regarding the organisation of the clinic. One concern was about time management:

'You come early to be first and it is maybe before six o'clock and you go home after three or four in the afternoon. Sometimes I felt nausea [sick] and it is also cold that early in the morning. Then you should wait in front of the gate because then it is not yet open.' (Participant 8, Grade 12)

Some of the participants felt that coming early to the clinic was a waste of time, as one could spend as many as eight hours at the clinic. Although the participants went to the trouble of arriving early, they felt that they were treated unfairly as the needs of the older women were seen to before their own. They also felt that the midwives wasted time. They observed that the midwives would sit, talk and laugh with one another or take long tea or lunch breaks whilst keeping the participants and other women in the clinic waiting.

The concerns related to wasting time are synonymous with the findings in a study conducted in Lesotho by Phafoli, Van Aswegen and Alberts (2007:17). In the current study, participants thought that it would have been better if they were informed about the delays when they occurred, or at least if an apology was expressed to show respect. In a positive relationship, the nurse-midwife in the context of the current study has two main roles (Searle, Human \& Mogotlane 2009:92). Firstly, the midwife needs to relate to the pregnant woman as one human being to another. Secondly, the midwife should create a positive attitude by being open and welcoming to the teenager, to form the foundation of a therapeutic midwife-woman relationship. In the current study, judging by the responses of the participants, the relationship between the midwife and the participants was poor.

Another organisational concern raised was related to privacy and confidentiality, which were directly linked to space. Participants expressed concern as to who was listening to information they were providing. The reason for this was that consulting rooms were situated too close to one another. During an ANC consultation a pregnant woman has the right to privacy. The participants expressed concern about the lack of privacy at clinics, thus questioning the protection of confidentiality. Confidentiality refers to the relationship between one person who conveys personal information to another person whom he or she trusts (Pera \& Van Tonder 2005:50). Confidentiality is the patient's right, and participants perceived this aspect of their care as lacking:

'I could say they are lacking space, you know. They talk about everything regarding patients ... so we just have to keep our minds about the things about whatever they are doing and talking about everything in front about us.' (Participant 10, Grade 9)
'... privacy ... yes, I will prefer that the young people should sit on one side and the older parents on the other side. For us ... us a clinic aside, because then teenagers are together and they can have their own conversations. Then it will be better for our group of younger people who are pregnant that we can be on our own.' (Participant 6, Grade 12)

Privacy is an important factor in any healthcare facility. Women are sometimes referred to tertiary healthcare facilities for further management, and the participants felt that they did not want the other women or peers to know when that happened. Without privacy this expectation of the participants - which in any case is a legal and ethical professional requirement - cannot be fulfilled.

In interviewing women the midwives are key role-players in obtaining as much information as possible to optimise a possible referral decision. An in-depth exploration of the woman's history may be necessary, and sometimes sensitive and private information is to be shared. The participants did not feel that they could express themselves freely during these interviews, since they were scared that because of congestion in the clinic and perceived disregard for their age, their privacy could not be guaranteed.

Confidentiality is concerned with how professionals manage personal information and ensure that only the rightful persons get exposed to it (Botma et al. 2010:17). Patient confidentiality is also emphasised as a right in terms of the Patient Charter (Constitution of the Republic of South Africa Act No. 108 of 1996). The participants suggested ways to better organise the clinics to protect their privacy as well as promoting comfort.

Sub-theme C: The pregnant teenagers felt that there are too few staff members and too many women to take care of

The goals of any medical unit are achieved by means of dividing the nursing activities amongst staff members in a logical and fair manner, as well as by co-ordination of the divided activities. Coordination in the unit reflects synchronisation of different activities such as ensuring adequate staff for different functions and also ensuring effective, efficient and quality nursing care in that unit (Muller 2003:150). At times it is not easy to meet these requirements because of staff shortages.

Staffing is mainly affected by and depends on staff turnover. Factors considered to be affecting staff turnover are absenteeism, which could be the result of sickness, retirement, leave, resignations or the death of members of staff ( $\mathrm{Nel} e t$ al. 2008:150). Furthermore, to fill vacant posts is a long process, that also adds to the difficulty in achieving staffing norms, hence the persistent shortage of staff in several healthcare facilities (Grobler et al. 2006:125). The person in charge of a clinic will then have to divide the work between the staff that are present, which may cause gaps in service. Participants identified the shortage of midwives at the clinics to be contributing to the low standard of ANC, making the clinic environment distressful and unattractive to them:

'I do not like it when there is [sic] only one or two nurses sometimes at the clinic. They work too slow [sic]. Sometimes the nurse will leave us and go to the other side ... for the other old 
people who are also sick and take a long time before she can come back to us ... Yes, they must look at other people who are sick also like old men and women on the other side and they come to us also ... there is $[$ sic] too many patients for the few nurses.' (Participant 6, Grade 12)

As a rule, teenagers usually have little contact with healthcare services, as they tend to be healthy. A pregnant teenager visiting an ANC clinic may not know how to act or what to expect. She may look up to the midwife as a person in whom she can confide and who will provide her with adequate information related to her pregnancy, depending on how she perceives the supportive behaviour of that midwife. Individuals are usually attracted to a person whom they feel they can trust to take care of their well-being. They will try to avoid a person whom they do not trust (Reeve 2005:121). It is part of a midwife's professional duty to act with responsibility, concern and respect (Searle 2004:228). For that reason, midwives should always act in a responsible and caring manner when dealing with women, especially teenagers who visit the ANC clinics.

The alienating ANC clinic environment perceived by the pregnant teenagers was emphatically related to their limited or non-clinic attendance. For this reason, recommendations in the form of guidelines were developed to assist midwives to create a clinic environment conducive to the needs of pregnant teenagers.

\section{Reaching the research goals}

The purpose of the research study was to explore and describe the perceptions of the pregnant teenagers of their ANC environment. From the data collected and analysed it emerged that the pregnant teenagers attending ANC clinics in the Nelson Mandela Metropolitan Municipality experienced problems with the ANC environment. The theme and sub-themes explaining these perceptions were described. It can be concluded that the study reached its goal. The last section of this article includes recommendations based on the main theme and related sub-themes to the midwives on how to enhance the ANC clinic environment in order to promote enthusiasm and committed ANC attendance amongst pregnant teenagers. This was the second objective of the study.

Reviewing the results of the study it becomes clear that the challenges that are faced by the teenagers can be reversed, and positive opportunities for experiencing a better ANC clinic environment can be provided. The following discussion focuses on the limitations of the study and recommendations for clinical practice in order to alleviate the negative perceptions of teenagers of their ANC clinic environment.

\section{Practical implications}

The increasing numbers of teenagers who become pregnant are not only causing a socio-medical concern but also contributing to not achieving the Millennium Development Goals. Owing to low employment status, teenagers could have difficulty in coping with the demands of parenthood, and thus at times may abandon the newborn and increase neonatal morbidity and mortality rates. ANC has been defined in this study as a period of assessment and devising most suitable management strategies for pregnant women. In South Africa one of the leading medical concerns is HIV and AIDS, and success in management of these in midwifery has been noted, but depends entirely on disclosure and testing, on how compliant women are, and on the stage of pregnancy at which treatment was commenced. Disclosure and testing, which comprise the first step in the management of this condition, could be highly influenced by how much the woman (teenager) has been supervised during pregnancy. Also the ANC clinic environment could be used to enhance health education related to use of contraceptives by teenagers.

In a clinic environment that is non-judgemental and stressfree to pregnant teenagers, it is possible to have as many of the teenagers as possible coming for testing and commencing the necessary treatment and supervision as early as possible. Health education and advice related to family planning and sexuality could be conducted as a means of empowering the teenager for future pregnancies. Antenatal supervision of pregnant teenagers is of the utmost importance, not only for midwifery purposes but also for parenthood guidance. Teenagers have been proved to lack parenting skills; hence their infants are often admitted to hospital with either gastro-intestinal tract problems or malnutrition. Therefore the recommendations suggested in this study will not only benefit South African pregnant teenagers but also teenagers internationally.

\section{Limitations of the study}

The study had the following limitations:

- Subjectivity of the questions: the researcher being an insider as a practising midwife and also exposed to some of the perceptions being shared by the participants had to be mindful of the need to be neutral, which at times was difficult to achieve.

- The study was limited to only low-risk pregnant teenagers, thus depriving the researcher of insight into the perceptions of those participants experiencing complications. They may have had different perceptions.

- That the research was conducted in English and Afrikaans only, as these are the languages the researcher understood. Some of the participants may have expressed themselves more clearly were they able to use their own language (Xhosa).

- Only 'older' teenagers (aged 18-19 years) were included in the study.

\section{Recommendations}

Recommended guidelines to ensure a clinic environment that could enhance teenager attendance are as follows:

- Proper communication skills should be taught to midwives working at ANC clinics to ensure efficient service delivery and utilisation by pregnant teenagers. Midwives need to go for training programmes such as seminars, often, to learn how to communicate effectively with teenagers, 
including pregnant teenagers. Such formal training would allow the midwives to understand the teenage mind and empower them with skills that would allow them to explain to teenagers the care given to them.

- Stable operating hours should be provided for pregnant teenagers to allow them to attend the ANC clinics whilst still attending school. For example, the hours 14:00-16:00 can be allocated for an after-school clinic once or twice a week to allow teenagers some time to attend.

\section{Conclusion}

This research study was initiated by the observation made by the researcher that some pregnant teenagers were unbooked or had made only a few visits to the ANC clinic when they were admitted for delivery. Some of these teenagers come as referrals for complications either in pregnancy or in labour. Teenagers who attended the ANC clinics regularly were more prepared for childbirth than those who did not, and if complications were diagnosed and treated early the outcome of the pregnancy was more likely to be successful for both mother and baby.

The researcher interviewed the pregnant teenagers to explore and describe their perceptions of the ANC clinic environment in order to understand their reasons for staying away from the clinic. Results revealed that because they perceived the clinic environment as not accommodating their needs, they found the environment to be unwelcoming and as a result stayed away from the clinic.

\section{Acknowledgements}

No extra funding was received to conduct the study. I acknowledge the contribution of the participants and the services of Ms Jackie Viljoen who provided editorial assistance on this article.

\section{Competing interests}

The authors declare that they have no financial or personal relationships which may have inappropriately influenced them in writing this article.

\section{Authors' contributions}

S.J. (Nelson Mandela Metropolitan University) prepared and wrote the manuscript, N.R. (Nelson Mandela Metropolitan University), a research student, assisted with the proofreading of the manuscript and J.S. (Nelson Mandela Metropolitan University) was the research co-supervisor and assisted with the final draft of the manuscript.

\section{References}

Botma, Y., Greeff, M., Mulaudzi, F.M. \& Wright S.C.D., 2010, Research in health sciences, Heinemann, Cape Town.

Brink, H., Van Der Walt, C. \& Van Rensburg, G., 2006, Fundamentals of research methodology for health care professionals, Juta, Cape Town.

Creswell, J.W., 2003, Research design: Qualitative, quantitative and mixed method approaches, Sage, Thousand Oaks, CA.

Cronjé, H.S. \& Grobler, C.J.F., 2007, Obstetrics in South Africa, Van Schaik, Pretoria.
De Vos, A.S., Strydom, H., Fouché, C.B. \& Delport, C.S.L., 2010, Research at grass roots, Van Schaik, Pretoria.

Department of Health, 2006, Third report on Confidential enquiries into maternal deaths in South Africa, 2002-2004, Government Printers, Pretoria.

Department of Health, 2008, Guidelines for Neonatal Care, Government Printers, Pretoria.

Fraser, D.M. \& Cooper, M.A., 2010, Myles textbook for midwives: An African context, Churchill Livingstone, London.

Gillham, B., 2009, Research Interviewing: The range of techniques. Maidenhead: Open University Press.

Grobler, P., Warnich, S., Carrell, M.R., Elbert, N.F. \& Hatfield, R.D., 2006, Human resource management in South Africa, Cengage Learning EMEA, London.

Harrison, D., 2008, 'Three ways to reduce teenage pregnancy in South Africa', paper prepared for the HSRC Youth Policy Initiative Roundtable 5: Teenage Pregnancy, Reserve Bank, Pretoria.

Hunter, B., Berg, M., Lundgren, I., Ólafsdóttir, A. \& Kirkham, M., 2008, 'Relationships: The hidden threads in the tapestry of maternity care', Midwifery 24, 132-137. $\mathrm{http}: / / \mathrm{dx}$.doi.org/10.1016/j.midw.2008.02.003, PMid:18378051

Irinoye, O., Oyeleye, A., Adeyemi, A. \& Tope-Ojo, V.A., 2004, 'Analysis of parents' and adolescents' concerns and prescriptions for management of teenage pregnancy in Nigeria', Africa journal of Nursing and Midwifery 6(1), 25-30.

James, S., Van Rooyen, M. \& Strümpher, J., 2010, 'The model for the facilitation ofintergenerational reconciliation in teenage pregnancy, A Xhosa perspective', African Journal of Nursing and Midwifery 12(2), 3-13.

Katzenellenbogen, J.M., Joubert, G. \& Abool, K.S., 2002, Epidemiology: A manual for South Africa, Oxford University Press, Cape Town.

Kaufman, C.E, De Wet, T. \& Stadler, J., 2001, 'Adolescent pregnancy and parenthood in South Africa', Studies in Family Planning 32(2), 147-160. http://dx.doi. org/10.1111/j.1728-4465.2001.00147.x, PMid:11449863

Kazembe, A., 2009, 'Factors that influence sexual behaviour in young women', African Journal of Midwifery and Women's Health 3(2), 67-73.

Kotzé, W., 2008, Nurse educators' guide to management, Van Schaik, Pretoria.

Krefting, L., 1991, 'Rigor in Qualitative research: The assessment of trustworthiness', American Journal of Occupational Therapy 45(3), 214-222.

Littleton, L.Y. \& Engebretson, J.C., 2002, Maternal, neonatal, and women's health nursing, Thomson Learning, Delmar.

Majangaza, S. \& Skiti, S., 2011, 'Thousands of Eastern Cape schoolgirls fall pregnant, Daily Dispatch, 09 March, 1.

Maree, K., 2010, First steps in research, Van Schaik, Pretoria.

Moultrie, T.A. \& McGrath, N., 2007, 'Teenage fertility rates falling in South Africa', South African Medical Journal 97, 442-443.

Muller, M., 2003, Nursing dynamics, Heinemann, Sandown.

Nel, P.S., Werner, A., Haasbroek, G.D., Poisat, P., Sono, T. \& Schultz, H.B., 2008, Human resource management, Oxford University Press, Cape Town.

Omoni, G.M., 2009, 'Teenage mothers in Kenya: Seduced, coerced and at risk of HIV', African Journal of Midwifery and Women's Health 3(1), 24-29.

Pattison, R.C., 2005, Basic antenatal care handbook, Maternal and Infant Healthcare Strategies Research Unit, Obstetrics and Gynaecology Department, Medical Research Council, Pretoria.

Pera, S.A. \& Van Tonder, S., 2005, Ethics in health care, Juta, Cape Town.

Phafoli, S.H., Van Aswegen E.J. \& Alberts U.U., 2007, 'Variables influencing delay in antenatal clinic attendance among teenagers in Lesotho', SA Fam Pract 49(9), 17.

Reeve, J.M., 2005, Understanding motivation and emotion, Wiley, New Jersey.

Republic of South Africa, 1996, Constitution of the Republic of South Africa, Act No. 108 of 1996, Department of Public Service and Administration, Pretoria.

Saadhna, P., Makiwane, M., Ranchod, C. \& Letsoalo T., 2009, Teenage pregnancy in South Africa: With a specific focus on school-going learners, Government Printers, Pretoria.

Searle, C., 2004, Professional practice: A Southern African Nursing Perspective, Heinemann, Pretoria.

Searle, C., Human, S. \& Mogotlane, S.M., 2009, Professional practice: A Southern African nursing perspective, Heinemann, Johannesburg.

Sellers, P.W., 2006a, Midwifery, vol. 1, Juta, Landsdowne.

Sellers, P.M., 2006b, Midwifery, vol. 2, Juta, Lansdowne.

Stuart, G.W. \& Laraia, M.T., 2005, Principles and practice of psychiatric nursing, Elsevier, Mosby, MO

Taylor, S.E., Peplau, L.A. \& Sears, D.O., 2003, Social psychology, Pearson Education International, New Jersey.

Saadhna, P., Makiwane, M., Ranchod, C. \& Letsoalo, T., 2009, Teenage pregnancy: with a specific focus on school-going learners, Unicef-Government Printers, South Africa.

Thompson, S., 2010, 'The complexities of supporting teenagers in pregnancy', British Journal of Midwifery 18(6), 368-372.

Tighe, S.M., 2010, 'An exploration of the attitudes of attenders and non-attenders towards antenatal education', Midwifery 26, 294-303. http://dx.doi.org/10.1016/j. midw.2008.06.005, PMid:18809230

Watson, R., Mckenna, H., Cowman, S. \& Keady, J., 2008, Nursing research designs and methods, Elsevier \& Churchill Livingstone, San Francisco, CA.

Yoder-Wise, P.S., 2007, Leading and managing in nursing, Mosby, Elsevier. 